\title{
Social Work as a Supplementary Treatment Option for Narcissistic Personality Disorders
}

\author{
Conny Löbert ${ }^{1} \&$ Carsten Giebe ${ }^{2,3}$ \\ ${ }^{1}$ Hochschule Fulda - University of Applied Sciences, Department of Social Work - Focus on Community \\ Psychiatry, Fulda, Germany \\ ${ }^{2}$ Szent István University, Doctoral School in Management \& Organizational Science, Kaposvár, Hungary \\ ${ }^{3}$ International Organization for Business Coaching (IOBC), Germany \\ Correspondence: Carsten Giebe, Szent István University, Doctoral School in Management \& Organizational \\ Science, Kaposvár, Hungary \& International Organization for Business Coaching e.V. (IOBC), Germany.
}

Received: February 9, 2021

Accepted: March 10, 2021

Online Published: March 12, 2021

doi:10.5539/ijps.v13n2p1

URL: https://doi.org/10.5539/ijps.v13n2p1

\begin{abstract}
This paper discusses selected scientific aspects of Narcissistic Personality Disorder. The main purpose of this research paper is to examine the extent to which patients with Narcissistic Personality Disorder can be supported and treated within the framework of social work-based community psychiatry. To this end, the Diagnostic and Statistical Manual of Mental Disorders will be used to address the problem of invisible distress and the difficulties of differential diagnosis. Furthermore, psychodynamic and behavioural treatment calculations are outlined. Based on this, differentiated and systematised considerations on concrete possibilities for social work-community psychiatric activities are made. In doing so, a model was developed which can guarantee a solid and goal-oriented orientation on the basis of the lifeworld of patients with Narcissistic Personality Disorder. Finally, possible problems in the effectiveness of social work in the context of Narcissistic Personality Disorder are discussed. The article is presented in the following order: Introduction and problem statement, Theoretical classification and research question, Methodological approach and model, Discussion and conclusions, and Limitations and directions for further research. The findings of this article may be useful for psychologists and social workers to identify and harness the potential of social work as a supplementary treatment option for Narcissistic Personality Disorder.
\end{abstract}

Keywords: narcissism, personality disorder, social work, social therapy, behavioural therapy

\section{Introduction and Problem Definition}

The tragedy of the narcissist is known to many. A man falls in love with himself and never would that ever change. The consequence is a compulsion to have to prove one's own excellence over and over again. Everyone seeks happiness in an individual way. In doing so, one bears the risks of the search oneself and under certain circumstances gets lost to oneself. Then one speaks of selfishness (Krusche, 2017). A real hype has arisen around narcissism in recent years. The term, coined by Siegmund Freud, has had a steep career in the past and can be found in bestsellers as well as in the daily press (Samol, 2019). Due to socially frightening events of the past, the term is flirted with. Kunstreich, for example, associates the term destructive narcissism with people who have run amok. So-called destructive narcissism invites denial of responsibility (Kunstreich, 2017). Narcissism and boundary violations are thus current across society. The much-discussed phenomena, such as abuse of power and the accompanying destructive potential of narcissism, shape the here and now and are now an everyday circumstance (Spitzer \& Strauß, 2019). Even more, narcissistic behaviours are now considered desirable almost everywhere. In the media, in the world of work, in politics, they are rewarded with admiration and recognition (Samol, 2019). It can be stated that narcissism is an ambiguous term in the context of personality disorders. The study evidence paints a picture with a large number of empirical studies on narcissism as a personality trait in healthy individuals. A lack is evident in studies of patients with Narcissistic Personality Disorder (NPD) (Lammers et al., 2013). It is possible that social work can provide valuable impulses for the treatment of NPD. Social work integrates various bodies of knowledge and findings from other scientific fields. A valuable basis and important foundation of social work is psychology as the science of human experience and behaviour. The results from the sub-disciplines of clinical psychology, developmental psychology and social psychology are 
indispensable for a profound understanding of the experience and behaviour of clients (Wälte et al., 2019). Furthermore, the main task of social work is to find ways to integrate and interact with all (Lyakh et al., 2020). Given the research gap described above, this article aims to answer the question of the potential added value of establishing a more comprehensive social work intervention. To this end, the first step is to describe the disorder, the diagnostic criteria and, in particular, the subjective suffering of NPD in order to gain a comprehensive understanding of the treatment and the significance of social work in this context.

\section{Theoretical Classification and Research Question}

\subsection{Theoretical Classification}

As far as the disorder is concerned, the diagnostic foundations of NPD were laid by Kohut and Kernberg in the 1970s. It is one of the so-called cluster B disorders and is defined in the Diagnostic and Statistical Manual of Mental Disorders (DSM V) with nine diagnostic criteria (see Table 1), of which at least five must be fulfilled. In general, the diagnostic criteria represent levels of data (e.g. psychological, social, biological) as well as different constructs (e.g. perception, emotion, behaviour). In order to make a stable, objective and differentiated diagnosis, it is important to examine several levels. Furthermore, more than $50 \%$ of the diagnostic criteria should be fulfilled for a diagnosis. The number and "intensity" of the fulfilled criteria can be an indication of the severity of the clinical picture. In the International Statistical Classification of Diseases and Related Health Problems (ICD-10), however, NPD is not listed as a separate diagnosis, but is only found under the category F60.8 "other specific personality disorders" (Kröber, 2008; Vater et al., 2013).

Table 1. Own representation "Diagnostic and Statistical Manual of Mental Disorders (DSM V)"

\section{Diagnostic criteria according to the DSM V}

1 Has a grandiose sense of one's own importance (e.g. exaggerates one's own achievements and talents; expects to be recognised as superior without corresponding achievements).

2 Is strongly taken in by fantasies of boundless success, power, glamour, beauty or ideal love.

3 Believes oneself to be "special" and unique and only to be understood by or to associate with other special or respected persons (or institutions).

4 Demands excessive admiration.

5 Exhibits a sense of entitlement (i.e. exaggerated expectations of particularly preferential treatment or automatic compliance with one's own expectations).

6 Is exploitative in interpersonal relationships (i.e. takes advantage of others to achieve own goals).

7 Shows a lack of empathy: Is unwilling to recognise or identify with the feelings and needs of others.

8 Is often envious of others or believes others are envious of him/her.

9 Displays arrogant, overbearing behaviour or attitudes.

In the DSM-V, there is also an alternative model that describes the disorder pattern of NPD. This explains what makes a diagnosis possible for all three subtypes (grandiose-malignant, vulnerable-fragile and exhibitionistic with a high level of functioning). This alternative model looks at the areas of identity, self-control, empathy and closeness in dealing with other people compared to healthy people. The perception of one's own identity is subject to strong fluctuations, as the self-concept is based on the feedback of others. Similarly, self-control is also characterised by the search for recognition from others. The capacity for empathy is described as limited, so that reactions of others are only taken note of if they are relevant to one's own person. Another social component in the disorder describes that "patients with NPD have no authentic interest in others and they use others exclusively to achieve their own goals" (Vater et al., 2013).

\subsection{Suffering Pressure and Consequential Problems}

In order to describe the problems in everyday life, it is relevant to first outline the suffering of NPD patients. The personality is characterised by a fragile self-esteem. This is overcompensated by a self-image of one's own greatness. To this end, facts are presented differently from the given and, above all, exaggerated. As a result, it is not uncommon for those affected to become entangled in lies in order to maintain their own credibility. The inner pressure increases steadily. By overestimating their own abilities, people with NPD often take incalculable risks. They perceive doubt and rejection from others as an enormous mortification and existential threat. If the inner pressure and the threat to their own self-image becomes too great, secondary problems often develop. Those affected feel increasingly alone and are dissatisfied with their life situation. Psychological sequelae such 
as depression and/or burn-out can develop. It is not uncommon for suicidal thoughts to occur during this phase. The problem can also manifest itself in psychosomatic disorders, such as high blood pressure, heart disease, stomach ulcers, but also sexual dysfunctions. In the interpersonal/social context, the disorder-specific problems can manifest themselves, for example, through relationship problems up to and including break-ups or a complete withdrawal. This does not only refer explicitly to a partner, but can also affect the entire social environment, as well as professional life (dismissal). On the other hand, addictions can also develop in an attempt to compensate for the pressure of suffering. These include alcohol and drug addiction and other behavioural addictions, such as excessive shopping, excessive sports and excessive media and mobile phone use (Berger, 2012).

\subsection{Diagnostic Difficulties and Comorbidities}

For most NPD patients, the exaggerated self-assessment and presentation precludes therapy without acute suffering. If there are no pathological difficulties, it may be possible to speak of a narcissistic personality dimension. Often, those affected seek help because of the above-mentioned consequences. Therapy due to NPD symptoms is usually only sought in an acute crisis. Acute crises can be comorbidities such as depression, bipolar spectrum disorders, somatisation disorders, anxiety disorders and especially addiction disorders. The diagnosis of NPD is not always clear-cut due to very similar symptoms of other personality disorders. The three most important ones will be briefly named here with their essential commonality, as well as the diagnostic differentiation criterion. The symptoms of NPD are very similar to borderline personality disorder, because both have severe restrictions in emotion processing. However, NPD sufferers do not react with self-injurious behaviour to regulate their emotions. Furthermore, there is a strong symptomatic similarity to histrionic personality disorder, as both have "a strong focus on the self, especially the dependence of one's own self-worth on external sources of self-worth". However, NPD is distinguished from histrionic personality disorder by the fact that the way in which it interacts with other people is essentially made dependent on the expected personal benefit. Finally, the antisocial or dissocial personality disorder should be mentioned. The common feature here is mainly a lack of emotional empathy, whereby an NPD diagnosis excludes impulsive and aggressive behaviour. However, the personality disorders mentioned above can also occur as comorbid personality disorders, which makes a clear diagnosis even more difficult. The sometimes difficult differentiation of the symptoms of the comorbid mental disorders, as well as the comorbid personality disorders, make a clear diagnosis and thus also the development of an appropriate treatment strategy difficult (Vater et al., 2013).

\subsection{Research Question}

According to Euler et.al, there are no manualised therapy approaches and no controlled therapy studies for the treatment of NPD to date (Euler et al. , 2018). Although social workers are on site during inpatient treatment, unfortunately they are not always extensively involved in treatment, especially in resocialisation. Resocialisation describes the reintegration into a subjectively and, if possible, objectively perceived positive living environment. In the field of outpatient therapy, this is even more rarely the case. Due to these circumstances, there is possibly wasted potential through the non-involvement of social workers. The following research question is formulated in conjunction with the research gap described under "Introduction and Problem":

"How can social work contribute to the treatment of Narcissistic Personality Disorder?"

\section{Methodological Approach and Model}

First, an exploratory literature search lasting several months was conducted with the aim of sifting through and categorising the scientific literature necessary for the research topic. Scientific literature and studies were searched for in scientific forums established for psychological issues (e.g. the databases PsycINFO or LIVIVO) and via the search function of the Fulda University and State Library. During the research, it was noticed that although there are numerous concepts and psychotherapeutic procedures for the treatment of personality disorders, these almost completely disregard the inclusion of social work. For this reason, it was not possible to fall back on a concrete scientific basis for this particular research question, so the research started with the psychological foundations. Therefore, the diagnostic criteria and the potential consequences of NPD were researched first. It is noticeable that, for example, at the peak of the course of the disease, the comorbid diseases (e.g. depression) are often diagnosed first. The dysfunctionality of lifestyle seems to be similar in NPD as well as in depression. Therefore, the focus of further essential research activities was on social work measures for depression. The keyword search was conducted in German. Keywords related to NPD and depression (NPD therapy, diagnosis, comorbid illness, measures for depression, behavioural therapy) as well as keywords related to social work (measures for the reintegration of mental illness, social work measures, social therapy) were linked. The most important results are summarised in a narrative form. 


\subsection{Therapeutic Intervention Options}

Due to the lack of controlled therapy studies, only some therapy options will be briefly outlined below to give an overall impression of treatment - therapeutic and social work. The best-known methods are based on the studies of Kohut and Kernberg, who made a significant contribution to the diagnosis of NPD in the 1970s. Kohut takes the aetiology as the basis of therapy, whereby the patient should experience a corrective relational experience through "the therapist's empathy, with the goal of post-maturing the infantile larger self" (Euler et al., 2018). The approach is characterised by the therapist's supportive and empathetic behaviour, with the aim of developing a more positive self-image that is not focused on the lasting admiration of others (Amrhein, 2014). In contrast, Kernberg describes a more confrontational therapy. Patients should be made aware "that their overestimation of themselves is a defence mechanism against anger, aggression and feelings of envy." This transference-focused therapy focuses on interpreting the behaviour in the current life (Euler et al., 2018). Another common method for treating NPD is cognitive-behavioural therapy. The basic therapeutic approach is based on Kohut's concept and relies on an appreciative relationship. Within the therapy, concrete, current problems should be addressed, and characteristic difficulties as well as unfavourable thought patterns of the patient should be worked out and gradually changed (Amrhein, 2014).

\subsection{General Framework Conditions}

Before describing the intervention possibilities of social work, it should be noted that a comprehensive treatment of NPD is only conceivable in combination with psychotherapeutic treatment. The nevertheless great benefit of an additional social work intervention will be explained in more detail below. There are some basic principles, such as the general educational-therapeutic goals. Although these also apply independently of the context, the following section will refer to social work interventions. These are intended either as part of the gradual phase-out of inpatient treatment or in addition to outpatient therapy. The social work measures are conceivable independently of the form of therapy. They complement each other best with Kohut's therapy or cognitive-behavioural therapy because of the recommended professional attitude described in more detail here.

The goals of treatment of NPD apply generally to therapeutic as well as social work interventions. One of these is the improvement of interpersonal interaction. This can be achieved by overcoming shyness, increasing the ability to empathise, reducing fear of possible negative evaluations and the resulting improvement in the ability to criticise. Secondly, personal resources should be strengthened. This includes developing a realistic self-assessment, increasing self-esteem, improving self-regulation and increasing frustration tolerance (Berger, 2012). The basis for a goal-oriented therapeutic as well as social work intervention is a stable relationship between client and professional. The professional should first and foremost be a "secure base" for the patient and always encourage him to work on the current relationship experiences. This corresponds to the conceptual design according to Kohut, as well as to cognitive-behavioural therapy. An appreciative basic attitude is the starting point of the interaction in order to avoid premature therapy interruptions and to work constructively on the patient's distortion of perception. Another important point in the basic professional attitude is the active and expressive nature of the professional, as this makes it clear to the patient that all personality traits are known and accepted (Schuhler 2014).

\subsection{Model Lifeworld and Spheres of Life}

In order to understand the extent to which social work can intervene in the emerging problems of NPD, these must first be presented in concrete terms. For a comprehensive overview, all relevant problems and fields of action were first compiled. Then a model - the social work lifeworld model for supplementary NPD treatment was developed (see Figure 1), which categorises the lifeworld into four areas listed in more detail below. This will also be useful later for the structured and systematic treatment of the research question. Based on the four areas of life - social, activity/life style, health and values/feelings - possible problems in connection with NPD are to be shown here. There is always a correlation between the individual areas and sub-areas. The values in particular are often directly related to the other areas of life. 


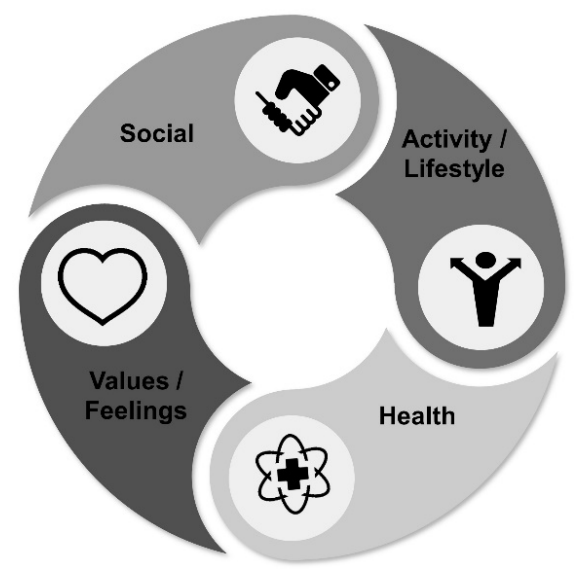

Figure 1. Own representation of the "social work lifeworld model for supplementary NPD treatment"

\subsubsection{Social}

The first area to be addressed at this point is the social environment. Basically, the problems perceived by all relatives in the social environment are similar. This includes parents, partners, children, colleagues, friends, etc. The differences become clear in the respective interpersonal relationships. The differences become clear in the respective interpersonal structures and the intensity of the relationships with the respective persons. In general, it can be said that NPD sufferers show very conspicuous social behaviour. On the one hand, they need the permanent admiration and recognition of others to strengthen their self-worth. On the other hand, they treat their fellow human beings disparagingly, among other things because of their low empathy capacity. They tend to manipulate and exploit their social environment, which ultimately leads to unsatisfactory interpersonal relationships (Amrhein, 2014). NPD sufferers usually do not yet seek therapeutic help. For this reason, the concrete description of the social problem situation refers to a depressive phase/depression as a kind of manifestation of NPD.

Basically, it can be said that during the course of NPD, interpersonal relationships are in a downward spiral. The distance to other people becomes greater and greater and it is not uncommon for relationships to end in breakdowns. The danger of social isolation arises (Epstein Rosen \& Amador, 2008). This usually refers to the circle of friends and the entire family context. NPD sufferers are often in a partnership relationship with a clear role structure. However, if they find themselves in the downward spiral of social isolation and the accompanying increasing dissatisfaction with their own life circumstances, these previously clear role structures change greatly, which can make it difficult to shape the relationship. A corresponding study even shows an increased divorce and separation rate (Frei et al., 2004). Narcissistic partners ensnare their partners with resourcefulness. Among other things, there are intense conflicts coupled with helplessness and despair. Narcissists find themselves in a dilemma between the need for commitment and the need for autonomy (Benecke, 2019). A special problem situation can develop in relation to the children of NPD sufferers. On the one hand, there is the development of the child, which, as with all parents with a personality disorder, can be severely affected. One speaks of an emergence of socially conspicuous behaviour, up to the development of a mental illness (Baer et al., 2013). On the other hand, there is the enormous self-centredness of the parent. If the children become neglected due to ignorance or comorbid problems such as depression, there is a risk of custody being withdrawn.

\subsubsection{Activity/ Lifestyle}

On the one hand, the area of lifestyle includes, as an essential point, the occupation and thus the financial security of the living conditions. On the other hand, there are private activities such as club memberships, hobbies and cultural activities. With regard to professional careers, it can be stated that narcissists are in most cases considered pioneers in their field. According to Csef (2016), they are often the driving force behind positive developments in politics, business, science and the arts. However, it is in line with the clinical picture of NPD that the urge for endless recognition and fame is generated by lies after a certain point. This not infrequently leads to enormous entanglements. The more the pathology of narcissism develops in the direction of a personality disorder, the greater the danger of a successful career collapsing (Csef, 2016). This can then lead to job loss, which can mean the collapse of financial security in the whole area of life. If depression develops as a comorbid or secondary disorder, this can lead to neglect. In extreme cases, this could lead to a process chain such as "lying through faulty self-representation - entanglement in the lies - setting of feelings of being 
overtaxed - exposure on the part of the employer - job loss - debts - loss of living space - neglect" (see Figure 2). Another possible consequence of job loss is the tendency to commit crimes, either to maintain the construct of lies and generate constant recognition, or to ensure continued financial security.

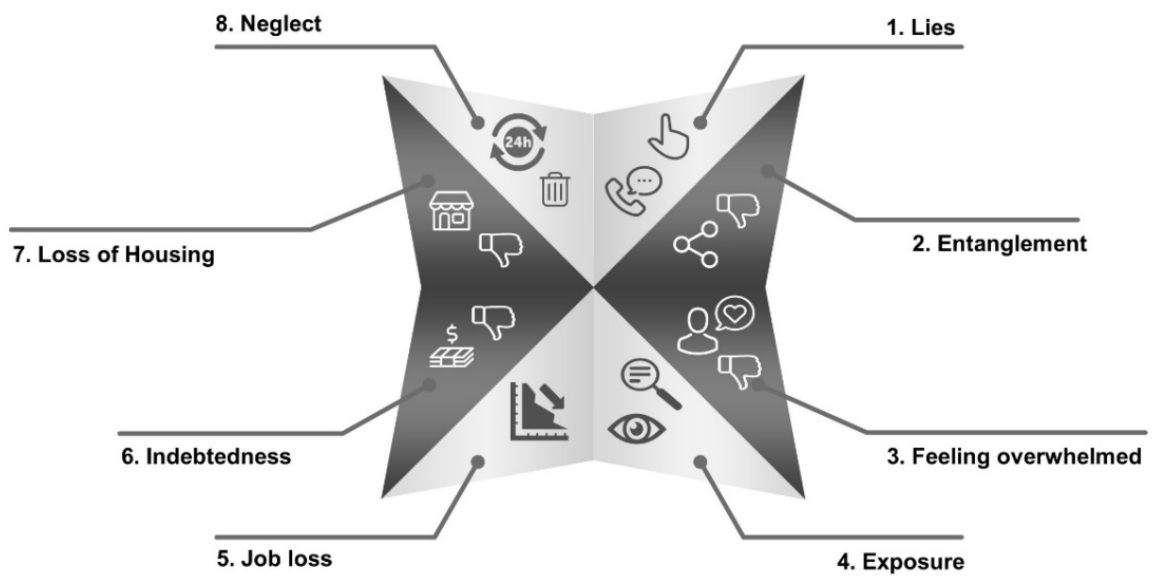

Figure 2. Own illustration "Systemic approach - using the example of a created process chain"

On the other side of the area of lifestyle are leisure activities, which can also end in discontinuation as a result of a pathological escalation of NPD. Here, too, those affected take incalculable risks as a result of purely expedient and self-enhancing behaviour (Berger, 2012). The field of sport should be mentioned here as an example. Due to excessive self-importance, it could happen that injuries are not prevented and permanent damage or impairments occur.

\subsubsection{Health}

The potential problems that can arise with NPD in the health context will only be briefly discussed here. On the one hand, physical health can be severely affected by the development of psychosomatic diseases. On the other hand, the development of comorbid mental secondary diseases is a major problem. These include, above all, addictive disorders and depression. In the case of depression as a comorbid consequence of NPD, the above-mentioned consequential problems such as job loss and social dropouts are significant. In the case of addiction, this can lead to criminal offences, for example substance abuse or acquisitive crime, but also to the development of permanent physical damage (Vater et al., 2013).

\subsubsection{Values/ Feelings}

Here, possible values and feelings are named which can be impaired as a result of the begrudging development of other areas of life. These can be seen as emotional starting points or as consequences of certain behaviours and events or developments in the other areas mentioned above. The generally valid values and feelings mentioned are contrasted with their reversals as potential problems. For example, the loss of happiness or being happy can lead to chronic dissatisfaction and even depression. The loss of self-esteem is not only a potential consequence, but also a diagnostic criterion of NPD, which should therefore not go unmentioned. Another value that could be lost through NPD is social recognition. Here, relationship breakdowns can lead to social exclusion an external decision - or social isolation - an internal decision (Euler et al., 2018). The values of "security, serenity and compassion" are strongly affected by NPD. The loss of these named issues results in feelings of internal pressure, compulsion, frustration, anger, hatred, envy and overwhelm. This is especially crucial with regard to the outside world, because due to the excessive increase of these negative feelings, it can happen that a so-called "destructive narcissism" develops. On the one hand, this includes affects against one's own self, but above all also external aggressions (Csef, 2016). As a result of external aggression, it can lead to the loss of the value of "freedom". Due to the development described above, people with NPD symptoms have an increased risk of becoming dangerous. In addition, the probability of committing criminal offences and being placed in custodial facilities increases (Stompe, 2008).

\subsection{The Lifeworld Model of Social Work for the Supplementary Treatment of NPD through Social Work Measures}

In principle, the idea of social work intervention possibilities is based on case management or social space and resource orientation (Müller, 2004). Essentially, social work measures are to be understood in the context of 
Bommes' and Scherr's definition of social work, which is largely understood as a mediation activity. The task of social work is to recognise exclusion tendencies and exclusion potential and, for example, to initiate legal, educational, social administrative or medical help in an external functional system (Bommes \& Scherr, 2000). The measures presented are conceivable by both hospital-internal and external social workers. However, the differentiated breakdown of what lies in whose sphere of possibility is not presented for reasons of scope. After the previously elaborated potential consequential problems of NPD through the classification of the areas of life, it is now to be shown to what extent social work could contribute to the desired goals through targeted measures. In order to achieve this, "practical" intermediate goals could be formulated. All the measures mentioned here are intended as a supplement to psychotherapeutic treatment and are not to be understood as a stand-alone offer of help. The measures described are conceivable in the context of a successful therapy that has ended or is nearing its end.

\subsubsection{Social}

One of the major consequential problems of NPD in the social sphere is the development of mutually unsatisfactory interpersonal relationships. In its aggravation, these could lead to resulting relationship breakdowns. In the practical field, this can be dealt with by establishing couple therapies and joint conflict talks with the relevant caregivers. This could be done in an outpatient and inpatient setting both therapeutically and socially. If this is not possible within the therapy, a social worker can already help with the establishment of such a therapy at this point. An expansion of this help would represent a long-term and flexible support, in which conflict and couple talks could also take place after the therapeutic discharge, if necessary. There is potential for the use of a social worker there. This person could either act as an intermediary to a help centre or by independently carrying out an intervention.

On the part of the person concerned, communication training, such as is included in social competence training, could mean an improvement in social skills and thus a restoration or improvement of social contacts (Hinsch \& Pfingsten, 2015). In the area of children, more far-reaching problems and thus differentiated intervention options become apparent. On the part of the person concerned, the social worker can initiate parenting training or parent training equivalent to communication training in order to improve the particular communication with the child and to create a better understanding of the parental role (Lund et al., 2001). In a modified form, this can also be ensured by establishing one of the many offers of help. These include, for example, socio-educational family support, parent-child cures, educational support or educational day groups. If custody has already been lost due to the relinquishment of responsibility, a social worker can help with a gradual resumption of contact, especially in cooperation with the youth welfare office. If the relationship between parents and child has already been severely affected, therapy for the children can be discussed in order to permanently (re-)establish a good relationship. All the aforementioned help serves to improve social skills and thus social reintegration. By creating increasingly satisfying interpersonal relationships, the well-being is to be increased and thus a decrease in the psychosocial symptoms of NPD is to be brought about.

\subsubsection{Activity/ Lifestyle}

In the area of lifestyle, the biggest potential problem resulting from NPD was identified as a possible loss of a job. Accordingly, the measures refer either to regaining the former employment relationship or to finding a new job. On the one hand, social work can help the person concerned with the job search and application process, and on the other hand, a plan for gradual reintegration can be drawn up together with the person concerned (possibly also with the employer). An example of such a procedure is the company reintegration management. Another consequence of job loss that has been pointed out is the accrual of debts. In this case, the social worker can develop a debt settlement plan with the patient or refer him to appropriate services. In the case of further problems such as the loss of a home or similar, the person concerned can also make use of the mediating skills of the social worker. In the private sphere, mediation activities and the implementation of a reintegration plan can also be used as social work measures. All measures here serve the purpose of reintegration into society and the restoration of a certain quality of life. Through the new behaviour and approaches learned in therapy, those affected should be shown that they no longer have to give in to the compulsion of lies and exaggerated self-presentation in order to be recognised for their work. This is intended to serve as a preventive measure to relieve the mental burden and reduce the inner pressure.

\subsubsection{Health}

In the area of health, the possibilities of social work measures are basically limited, as this is the field of activity of therapists and doctors. Since a comorbid disease of NPD is an addiction disease, a possible social work measure for relapse prevention would be to jointly seek out a self-help group or also to move to a new 
environment in order to ensure staying away from harmful social circles. In order to limit the feeling of being overwhelmed by the multitude of therapies, the social worker can work out a plan together with the person affected and regularly check it for functionality.

Clinical social work is an exception. Social work measures for reintegration into the four areas of life are also partly carried out by the clinical social work. It must be taken into account that these measures are no longer financed when the therapy ends and are thus terminated. In order to nevertheless enable continued help, case management has become increasingly established in recent years. This individual case assistance is characterised in particular by intensive networking. However, the relevant literature repeatedly criticises the fact that case management is mainly used to shorten the length of stay in hospitals and psychiatric clinics. As a result, case management is subject to quality losses due to feheling differentiation from system management (Ewers, 1997). Accordingly, the measures presented in this research paper are sometimes similar to those in case management. They can therefore be seen as a useful extension of it. Nevertheless, the specific methods and the assistance in all four areas of life result in a unique selling point of the assistance.

\subsubsection{Values/ Feelings}

The extent to which social work measures have a positive influence on the feelings and values of those affected has already been explained. The explicit processing of the emotional world and the inner attitude is again reserved for therapists and psychologists. The social work measures can refer to a good cooperation between therapists and social workers, so that therapy and practical measures can benefit from each other. Furthermore, a good relationship with the social worker as well as the therapist can have a positive influence on the self-esteem of the person concerned. This would reduce the symptom burden and mean a better chance of a regulated life that is satisfactory for the person affected (Vater et al., 2013). The recovery of desirable goals is promoted, among other things, through the development of skills, which can ultimately also lead to an improvement in the quality of life. This involves the targeted practice of behaviours in order to avoid previously harmful situations. Skill training from dialectical behavioural therapy can be mentioned here as an example. In this way, for example, a (renewed) stay in a custodial institution could be avoided in the case of a comorbid addiction disease, and thus the value of freedom could be maintained.

\section{Discussion and Conclusions}

\subsection{Possible Problems in Treatment and a Social Work Approach to Solving Them}

Within the treatment of NPD, despite comprehensive support and therapeutic services, problems can arise that can only be addressed at the moment of emergence. Some of these challenges will be outlined in this section. This may lead to the realisation that a linear treatment according to a standard is not possible and that the individual problems should be taken into account in each case in an appropriate therapy and resocialisation planning. For better clarity, a potential follow-up problem is shown for each area of life in the familiar structure (see Figure 3). Directly after the problem is presented, a social work measure is described that could offer a solution to this challenge.

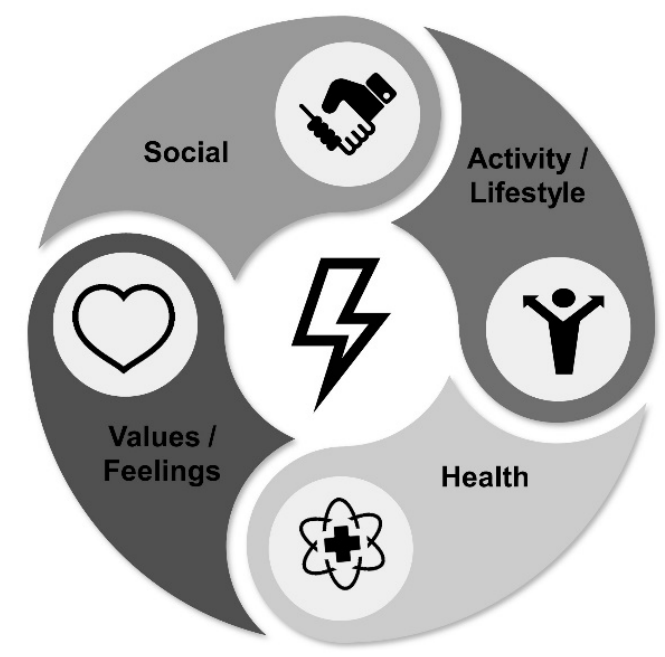

Figure 3. Own illustration "Social work lifeworld model for supplementary NPD treatment - Possible problems in treatment" 


\subsection{Social}

In the social sphere, unpredictable changes in life circumstances in particular can cause a new situation of excessive demands. This in turn could lead to a renewed worsening of somatic symptoms or a relapse into old behavioural structures (Schuhler, 2014). Examples of this are, among others, unplanned pregnancies, the death of close relatives or an unexpected separation from the partner. If, as a result, there is a relapse into old behavioural patterns of social interaction, it would also be an option to offer a counselling centre for the relatives. In this way, they could confidently turn to professionals, possibly even to the supervising social workers, in order to jointly develop a strategy for action. Furthermore, there should also be a possibility for those affected by an NPD disorder to consult their trusted carers/social workers again. Since it is part of the symptomatology of NPD to tend not to seek external help oneself (Amrhein, 2014), it should be considered whether the disengagement from therapy can be thought of as creeping out in the long term. In this way, the social worker could inquire about the current state of affairs in a fixed appointment without the person concerned having to ask for help on their own. Another possibility to address the needs and concerns of affected persons and relatives alike would be to refer them to a subsequent family or couples therapy.

\subsection{Lifestyle}

In the area of life management, the sometimes unstable professional perspective is a particular potential problem. Although there is a state-supported company reintegration management system in Germany, this explicitly shows strong deficits in the reintegration of mentally ill people. Numerous problems were identified that could be dealt with in particular through social work interventions. First and foremost, the wishes of the person affected must be followed in order to maintain the established relationship between the social worker and the person affected. This could look, for example, like naming the advantages of accompanied resocialisation and the patient then deciding whether and to what extent he or she wants to make use of these measures. Through scheduled target agreements, an improved fulfilment of these can be pursued. First and foremost, the problem of finding a suitable job in which comprehensive integration is possible is mentioned (Gröben et al., 2011). This problem also arises on the part of the NPD affected person, because a professional re-entry presupposes the actual existence of professional competences. But often it is merely an exaggerated self-assessment, as is symptomatically often the case. By creating a competence profile, realistic assessments of one's own abilities can be developed. This could help to find a suitable and possibly new occupational field from the outset. Through joint research with the social worker, an employer could then be found at the patient's request where good integration management is possible. An important core problem is described by the fact that the contact to external help institutions (e.g. counselling centres) and help providers (e.g. health insurance companies) is long and complicated (Gröben et al., 2011). This could be coordinated by accompanying a social worker and his or her network, so that faster help can be guaranteed in case of problems (Baer \& Cahn, 2008). A similar problem is posed by the lack of expertise in mental illness among local managers and employees, as well as the often resulting excessive demands on employers. On the part of the person affected, fears of stigmatisation can arise (Gröben et al., 2011). These challenges can be overcome by seeking social work help. A trialogue could take place between the employer, the person affected and the social worker. This presupposes a concrete agreement with the NPD affected person so as not to embarrass him. He or she decides what is to be said, to what extent, and who is to do what. In this way, ideas and wishes for the work can be addressed concretely and false expectations can be avoided. A preceding trialogue also establishes contact between the social worker and the employer for the first time. In the course of reintegration, this may also make it easier for both sides to talk things through in a crisis situation.

\subsection{Health}

In the area of health, the follow-up problem of a relapse is to be addressed by looking at the comorbidity of an addiction disease (Schuhler, 2014). In essence, a social worker could already preventively look for a suitable self-help group together with the NPD affected person, which would represent a contact person in times of crisis. Another possibility, as already mentioned, would be a long-term gradual resocialisation. In this case, there should be a cyclical feedback between the social worker and the person affected, in which the current state of health is queried. If necessary, a counselling centre could be sought or a renewed or refreshed addiction therapy could be carried out.

\subsection{Values/ Feelings}

In the area of values and feelings, three consequential problems are pointed out at this point, as the special features of NPD are to be included here. First of all, the feeling of being overwhelmed is mentioned, which can occur as a consequence of a multi-layered and comprehensive therapy. This refers to follow-up therapies, groups, 
time-intensive leisure activities and full-time work. In the case of NPD, excessive demands are a possible cause for becoming entangled in lies, which would reinforce a relapse into old behavioural patterns. One way to prevent this potential problem would be to coordinate the designated activities comprehensively. Regular queries during the resocialisation phase would then check the planning of any increases in time involvement in these activities for excessive demands (Herwig-Lempp \& Kühling, 2012). All interpersonal relationships are increasingly about dialogue. If disruptions occur in this process, they can sometimes lead to problems. According to Kölling, disruptions are considered shaming. Shame, in turn, is considered a guiding emotion in narcissism, along with anger and emptiness (Kölling, 2013). Therefore, the second major follow-up problem in NPD treatment is the shame of actually seeking mediated help at the end or after therapy. As mentioned above, it is symptomatic for NPD that those affected do not perceive help due to pride and overestimation of their own abilities. The extent to which this can be comprehensively resolved through previous therapy is crucial for the development of this problem. This is a potential follow-up problem in treatment, since any help can only be installed with the consent of the person concerned. One of the few possibilities is the aforementioned long-term creeping help, in which the social worker establishes contact with the affected person and offers his help under the guise of professional duty. A trusting therapeutic relationship is the cornerstone of the interaction (Vater et al., 2013). The last important point in naming the potential challenges in the area of feelings is professional distance. This follows on from the problem described earlier, as the focus here is on the loss of the trusting relationship between professional and affected person (Euler et al., 2018). This also goes hand in hand with disengagement and poses a problem for successful reintegration into all areas of life. If trust in the social worker diminishes, any problems are not communicated extensively and the likelihood of worsening symptoms increases. In order to address this problem in the best possible way, one option is to appoint the social worker as the contact person for all parties involved, such as partners, family and employers, from the outset. In this way, they can give feedback when a deterioration or crisis in the person affected becomes apparent, so that the social worker can again establish more intensive contact. At best, this could strengthen the relationship of trust again. If the contact breaks down completely, at least a crisis centre or another counsellor could be referred so that the condition does not deteriorate too much (Vater et al., 2013).

\subsection{Conclusions}

\section{Effectiveness and conclusion}

In this article, the research question was formulated as to how social work can contribute to the treatment of NPD. The research question could be answered in detail. It was shown to what extent social work measures can facilitate integration into a healthy psychosocial environment. On the one hand, it was shown to what extent measures in the context of separation from inpatient and/or outpatient therapy could be of help. On the other hand, it was described how social work interventions could contribute to an improvement and maintenance of positive developments even after the completion of therapy. In this context, social work can be implemented both by an external agency as well as by a long-term outsourcing by means of a staff member of the therapeutic facility. With all the possibilities of social work interventions mentioned, psychotherapeutic treatment must not be disregarded. It forms the cornerstone for the above-mentioned measures, as it is here that old behavioural, belief and thinking patterns are broken down and worked on (Vater et al., 2013). The treatment of NPD is not conceivable through social work alone. However, the combination of social work and therapy could primarily bring about a long-term improvement in the subjective feeling of illness (characterised by pressure, shame, anger and excessive demands) as well as the objective perception of the person affected (mainly characterised by social competence towards others). Here, care or support can be provided in crisis situations that arise, which cannot be represented to this extent by a therapist. The special feature of social work at this point is its mediating function and personal case management, which enables individual and practical help that is close to the living environment.

\section{Boundaries and Directions for Further Research}

In this paper, long-term creeping care is described as a social work measure. According to studies, this is not yet a common procedure in the inpatient and/or outpatient treatment of NPD. Here, however, flexible support beyond the actual therapy period could mean a particular improvement. Long-term periods of five years, for example, could be an option. During this period, the social worker could contact the person concerned again and again in order to have a consultation and to reflect on the areas of life together.

The existing myth about the young narcissist seems to be vulnerable to attack by science. It is interesting that a 16-year-old teenager does not recognise himself in the mirror image. However, this ability is learned around the age of one (Elendt, 2019). We also recommend first critically examining the theoretical approach developed. In 
the book review of Ian Shaw's "Social Work Science", Salustowicz asks how much research-based knowledge is contained in everyday social work. The answer, he says, is evidence-based enquiry (Salustowicz, 2020). For this reason, a field trial with appropriate feedback from practice would also be recommended for the findings of our research in a further step.

In an empirical study, Neumann observed two subtypes of narcissism - overt narcissism and covert narcissism. Overt narcissism is observable in behaviour, while covert narcissism is hidden behind an insecure demeanour. Overt narcissism is associated with high self-esteem, whereas covert narcissism is associated with low self-esteem (Neumann, 2010). Narcissists have an affinity for leadership positions. In this way, the desire for recognition and admiration can be satisfied. They are often initially perceived as charismatic, competent leaders. The positive impression can then turn negative when the self-absorbed and arrogant nature becomes more apparent (Heißenberger \& Haider, 2020). Narcissism is seen as a risk for managerial lapses. The increased awareness of the problem should have a positive effect in the future. Any preventive measures taken by business should be enriched by collective change and interdisciplinary interventions, such as psychotherapy or pedagogy (Csef, 2016). These different manifestations of narcissism or the roles of persons with NPD in the professional context could not be explicitly dealt with in our approach, so that there may be a need for further research here.

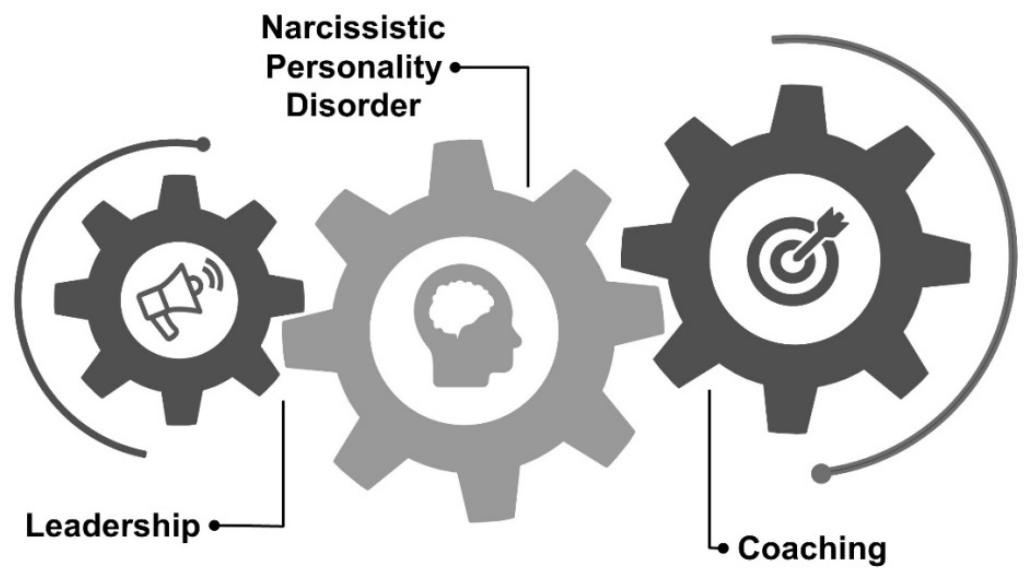

Figure 4. Own illustration "Possible directions for further research"

In the course of our research, an intersection between NPD and coaching was also discovered, but not considered due to the focus on social work. Some thoughts are therefore only rudimentary. Coaching persons with narcissistic tendencies sometimes leads to implicit fears and stress for the coaches, which can be described as unpleasant, threatening or overwhelming. Furthermore, destructive behaviours such as intransigence and change avoidance are reported in the coaching process. Mindfulness exercises could be a successful strategy, especially as the focus in recent years has been on success factors rather than possible problem areas (Diller et al., 2020). There is an area of tension when coaching managers, as personalities with strong narcissistic parts can often be found among managers. These narcissistic parts can show themselves as charismatic gifts. In order to be able to use a narcissistic relationship structure in a goal-oriented way in coaching, it is necessary that the coach knows his own narcissistic parts as well as possible. Only in this way can he behave appropriately in the face of possible devaluations or adulation on the part of his coachee (Schmidt-Lellek, 2004). Here, too, open questions arise. Given that coaching, similar to social work, is a field that has been little studied scientifically, further research is possible into the extent to which coaching can benefit managers with NPD (see Figure 4).

\section{References}

Amrhein, C. (2014). Von Narzissmus - Narzisstische Persönlichkeitsstörung, Narzissten. Retrieved from https://www.therapie.de/psyche/info/index/diagnose/persoenlichkeitsstoerungen/narzissmus/

Amrhein, C. (2014). Von Persönlichkeitsmerkmale als störende Belastung - Kategorien, Cluster und Häufigkeit. Retrieved

from https://www.therapie.de/psyche/info/index/diagnose/persoenlichkeitsstoerungen/kategorien-und-haeufigkeit / 
Baer, N., \& Cahn, T. (2008). Das Konzept der Gesundheitsdeterminanten. In K. Meyer (Ed.), Gesundheit in der Schweiz-Nationaler Gesundheitsbericht 2008 (pp. 211-230). Bern: Hans Huber.

Baer, N., Schuler, D., Füglister-Dousse, S., \& Moreau-Gruet, F. (2013). Depressionen in der schweizer Bevölkerung. Daten zur Epidemilogie, Behandlung und sozialberuflichen Integration. Obsan.

Benecke, H. (2019). Narzissmus in Partnerschaft und Paartherapie. PiD-Psychotherapie im Dialog, 20(3), 63-68. https://doi.org/10.1055/a-0771-7168

Berger, M. (2012). Psychische Erkrankungen - Klinik und Therapie. Urban \& Fischer, München. (4. Auflage 2012)

Bommes, M., \& Scherr, A. (2000). Soziale Arbeit, sekundäre Ordnungsbildung und die Kommunikation unspezifischer Hilfsbedürftigkeiten. In R. Merten (Ed.), Neue Ansätze und veränderte Perspektiven (pp. 67-86). Wiesbaden: VS Verlag für Sozialwissenschaften (Lehrtexte Erziehung). https://doi.org/10.1007/978-3-322-80858-5_6

Csef, H. (2016). Narzissmus und Derailment-wenn Führungskräfte entgleisen. Organisationsberatung, Supervision, Coaching, 23(2), 163-171. https://doi.org/10.1007/s11613-016-0451-7

Csef, H. (2016). Pathologischer Narzissmus und Destruktivität. Nervenheilkunde, 35(12), 858-863. https://doi.org/10.1055/s-0037-1616457

Diller, S. J., Stadlinger, C., Eberhard, I., \& Jonas, E. (2020). Ich bin perfekt-ich brauche kein Coaching! $\begin{array}{llll}\text { Organisationsberatung, } & \text { Supervision, } & \text { Coaching, }\end{array}$ https://doi.org/10.1007/s11613-020-00673-5

Elendt, D. (2019). Homöopathie, Wissenschaft und Narzissmus. Ein Essay. Homöopathie: Verlaufsbeobachtung, Therapieziele und Kriterien der Heilung Kongressband. Retrieved from https://www.wisshom.de/whwp/wp-content/uploads/2019/12/ICE18_Manuskript_gesamt_191111.pdf

Epstein Rosen, L., \& Amador, X. F. (2008). Wenn der Mensch, den du liebst depressiv ist. Wie man Angehörigen oder Freunden hilft (6. Aufl.). Reinbeck bei Hamburg: Rowohlt Taschenbuch.

Euler, S., Stalujanis, E., \& Spitzer, C. (2018). Aktueller Stand der Psychotherapie von Persönlichkeitsstörungen. Zeitschrift für Psychiatrie, Psychologie und Psychotherapie, 66(2), 95-105. https://doi.org/10.1024/1661-4747/a000345

Ewers, M. (1997). Case Management in der klinischen Versorgung. Zeitschrift für Gesundheitswissenschaften, 5(4), 309-322. https://doi.org/10.1007/BF02955890

Frei, Adrian, Ajdacic-Gross, V., Rössler, Wulf, \& Eich-Höchli. (2004). Auswirkungen von depressiven Störungen auf objektive Lebensbereiche. Psychiatrische Praxis, 31. https://doi.org/10.1055/s-2003-814822

Gröben, F., Freigang-Bauer, I., \& Barthen, L. (2011). Betriebliches Eingliederungsmanagement von Mitarbeitern mit psychischen Störungen. Prävention und Gesundheitsförderung, 6, 229-237. online publiziert: Springer Verlag. https://doi.org/10.1007/s11553-011-0306-1

Heißenberger, P., \& Haider, U. (2020). Die Dunkle Triade: Narzissmus, Machiavellismus und (milde) Psychopathie im Bildungswesen. $R \quad \& \quad E-S O U R C E$, 20(14). Retrieved from https://journal.ph-noe.ac.at/index.php/resource/article/view/835

Herwig-Lempp, J., \& Kühling, L. (2012). Sozialarbeit ist anspruchsvoller als Therapie. Zeitschrift für systemische Therapie und Beratung, 30(2), 51-56. Retrieved from https://www.herwig-lempp.de/daten/ZSTB-2012-2013-Sozialarbeit-ist-anspruchsvoller-als-Therapie-13042 1-alle.pdf

Hinsch, R., \& Pfingsten, U. (2015). Gruppentraining sozialer Kompetenzen GSK: Grundlagen, Durchführung, Anwendungsbeispiele. Retrieved

from https://katalog.ub.uni-heidelberg.de/cgi-bin/titel.cgi?katkey=66329924

Kölling, W. (2013). Variationen über Narzissmus. Organisationsberatung, Supervision, Coaching, 20(4), 437-446. https://doi.org/10.1007/s11613-013-0346-9

Kröber H.-L. (2008). Narzissmus. Forensische Psychiatrie, Psychologie, Kriminologie, 2(4), $271-272$. https://doi.org/10.1007/s11757-008-0098-0

Krusche, D. (2017). Selbst-Sucht 'und das Lächeln der Melania Trump-Stereotypie und Krankheit. IZPP, 16. Retrieved from https://www.izpp.de/fileadmin/user_upload/Ausgabe-1-2017/001Editorial_1_2017.pdf 
Kunstreich, T. (2017). Zur Aktualität des destruktiven Narzissmus. Forum der Psychoanalyse, 33(2), 185-190. Springer Medizin. https://doi.org/10.1007/s00451-017-0273-z

Lammers, C. H., Vater, A., \& Roepke, S. (2013). Narzisstische Persönlichkeitsstörung. Der Nervenarzt, 84(7), 879-888. https://doi.org/10.1007/s00115-013-3772-1

Lund, B., Rheinberg, F., \& Gladasch, U. (2001). Ein Elterntraining zum motivationsförderlichen Erziehungsverhalten in Leistungskontexten. Zeitschrift für pädagogische Psychologie, 15(3/4), 130-143. https://doi.org/10.1024//1010-0652.15.34.130

Lyakh, T., Spirina T., \& Rogozhynska V. (2020). Prinzipien der interdisziplinären Interaktion in der Sozialarbeit. Aktuelle Geisteswissenschaften, 3(27), 224-228. https://doi.org/10.24919/2308-4863.3/27.203727

Müller, J. (2004). Psychodrama in der Sozialarbeit. In v. Ameln, Gerstmann, \& Kramer (Eds.), Psychodrama (pp. 503-512). Berlin-Heidelberg: Springer Verlag. https://doi.org/10.1007/978-3-540-89913-6_30

Neumann, E. (2010). Offener und verdeckter Narzissmus. Psychotherapeut, 55(1), 21-28. https://doi.org/10.1007/s00278-009-0714-2

Salustowicz, P. (2020). Social work science: by Ian Shaw, New York, Columbia University Press, 2016, 344 pp. European Journal of Social Work. https://doi.org/10.1080/13691457.2020.1857017

Samol, P. (2019). Narzissmus als Norm: Psychische Deformation in der Spätkapitalistischen Gesellschaft. Widerspruch: Beiträge $z u$ sozialistischer Politik, 38(77), 71-78. Retrieved from https://www.ssoar.info/ssoar/handle/document/65138

Schmidt-Lellek, C. J. (2004). Charisma, Macht und Narzissmus. Organisationsberatung, Supervision, Coaching, 11(1), 27-40. https://doi.org/10.1007/s11613-004-0004-3

Schuhler, P. (2014). Der selbstbewusste Persönlichkeitsstil - Die narzisstische Persönlichkeitsstörung. Psychotherapie im Dialog, 3, 64-67. https://doi.org/10.1055/s-0034-1388640

Spitzer, C., \& Strauß, B. (2019). Narzissmus und Grenzverletzungen in der Psychotherapie. Psychotherapeut, 64(6), 429-429. https://doi.org/10.1007/s00278-019-00385-x

Stompe, T. (2008). Persönlichkeitsstörungen und Gefährlichkeit. psychiatrie \& psychotherapie, 4, 5-13. https://doi.org/10.1007/s11326-008-0001-9

Vater, A., Roepke, S., Ritter, K., \& Lammers, C. H. (2013). Narzisstische Persönlichkeitsstörung. Psychotherapeut, 58(6), 599-615. https://doi.org/10.1007/s00278-013-1021-5

Wälte, D., Borg-Laufs, M., \& Brückner, B. (2019). Psychologische Grundlagen der Sozialen Arbeit. Kohlhammer Verlag.

\section{Copyrights}

Copyright for this article is retained by the author(s), with first publication rights granted to the journal.

This is an open-access article distributed under the terms and conditions of the Creative Commons Attribution license (http://creativecommons.org/licenses/by/4.0/). 